\title{
ANÁLISE DA ESTRUTURA DO MERCADO BRASILEIRO DE CAMINHÕES, 1990-2010
}

\author{
Alberes Sousa Ferreira' \\ Jader Fernandes Cirino²
}

\section{Resumo}

O presente artigo teve como objetivo analisar a estrutura de mercado da indústria brasileira de caminhões no período de 1990 a 2010, dado que este setor mostra-se de fundamental importância para o desenvolvimento econômico do país ao promover a integração dos demais setores e/ou regiões em toda estrutura produtiva e de distribuição. O referencial teórico utilizado para a análise baseou-se na abordagem da Organização Industrial sob o Paradigma Estrutura-Conduta-Desempenho, buscando-se investigar os principais elementos que caracterizam a estrutura de mercado, dentre eles: a parcela de mercado, a taxa de concentração e o índice sumário de Herfindahl-Hirschman. Os dados para a análise foram obtidos através de publicações da ANFAVEA (Associação Nacional dos Fabricantes de Automóveis). A análise permitiu a conclusão de que o mercado estudado se encontra fortemente oligopolizado, além de apresentar barreiras à entrada de novas firmas.

Palavras-chave: Estrutura de Mercado, Índice de Herfindahl-Hirschman, Barreiras à Entrada

Classificação JEL: L1; L11; L62

Bacharel em Ciências Econômicas pela Universidade Federal de Viçosa (UFV) e mestrando em Economia Aplicada pela mesma instituição no Departamento de Economia Rural, e-mail: alberesasf@yahoo.com.br.

2 E-mail: jader.cirino@ufv.br 


\section{INTRODUÇÃO}

Nos últimos anos, o Brasil vem se destacando como um dos maiores produtores de veículos automotores do mundo, com destaque para o setor de caminhões. De acordo com os dados da Associação Nacional dos Fabricantes de Veículos Automotores (ANFAVEA, 2013a) o país se tornou a quinta maior indústria de caminhões do mundo em 2005. Estima-se que desde a criação desta indústria, em 1957, até o ano de 2005, tenham sido produzidos cerca de 2,8 milhões desses veículos no país.

Segundo informações da Anfavea (2013b) o peso da indústria de caminhões no setor automotivo era muito grande entre os períodos de 1957 e 1960, chegando a representar 48,10\% da produção dos veículos produzidos no país. No ano de 2008 esta representatividade já se mostrava muito modesta, somando apenas 5,2\% do total de veículos produzidos no Brasil. Embora essa indústria tenha perdido espaço frente aos outros segmentos do ramo automotivo, ainda firma-se como o principal expoente da matriz de transportes no Brasil. Segundo informações da Confederação Nacional de Transportes (CNT, 2013), o modal rodoviário responde por $65 \%$ das operações de transporte no país, contra cerca de $20 \%$ do ferroviário e $1 \%$ do transporte aquaviário.

Após anos apresentando baixas taxas de crescimento, a produção de caminhões apresentou um crescimento de 167,3\% - de 71,7 mil para 191,6 mil- entre os anos de 2000 e 2010 . Atualmente, estima-se que a frota de caminhões no Brasil seja de 1,7 milhões de veículos. Esse aumento da produção foi induzido pelas alterações ocorridas na economia brasileira nas últimas décadas. De acordo com Gitahy e Bresciani (2003), durante a década de 1990, ocorreram muitas transformações na indústria automobilística brasileira, dentre as quais pode-se destacar o acirramento da concorrência no mercado internacional e o lento processo de abandono da política de substituição de importações. Fatores que podem ter incentivado o aumento da produtividade neste setor, uma vez que a indústria doméstica não contava mais com a proteção tarifária instituída pelo governo.

A demanda por caminhões também acompanhou o aumento da produção durante o período analisado. $\mathrm{O}$ aumento das vendas internas no mercado de atacado (da fábrica para a concessionária) pode ser observado 
no Gráfico1. Nota-se que, embora existam períodos onde ocorrem reduções no número de caminhões vendidos, há uma tendência de elevação desse número durante o período observado.

Gráfico 1 - Evolução das vendas de caminhões no mercado de atacado brasileiro, 1990-2010

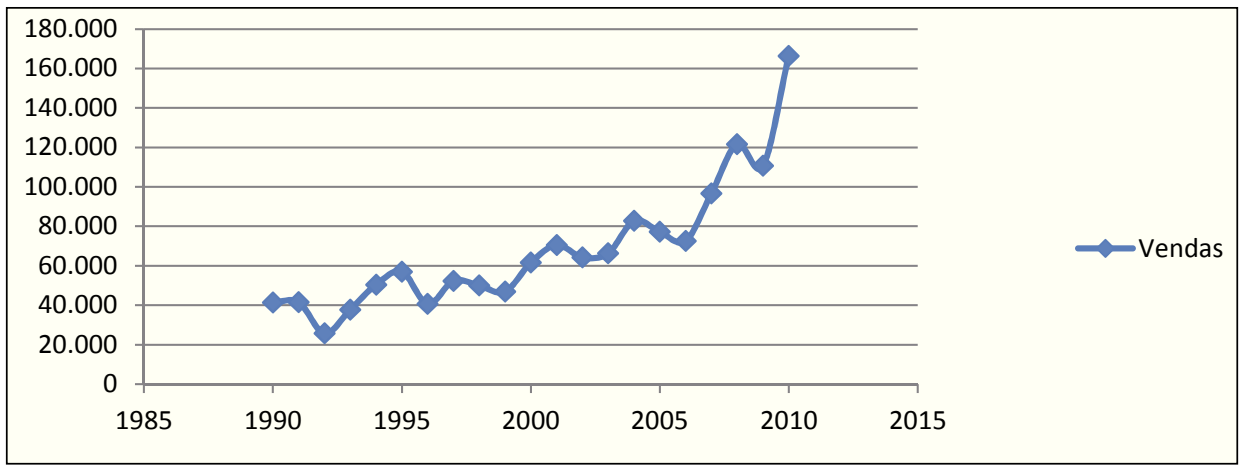

Fonte: elaborado pelos autores a partir dos dados da Anfavea (2013a).

Este vertiginoso crescimento da demanda por caminhões no país associa-se ao crescimento da demanda por transportes para o escoamento de commodities para os portos brasileiros. De acordo com a Associação de Comércio Exterior do Brasil (AEB, 2012), o país vem apresentando um crescimento acelerado de exportações de commodities ao longo dos últimos anos, principalmente entre os anos de 2000 e 2011. Entretanto, Gaban (2013) indica que o modal rodoviário apresenta altos custos variáveis e que o volume movimentado é pequeno, desse modo, verifica-se a necessidade de se realizar várias operações para assegurar o escoamento da produção (commodities em sua maioria) tornando o custo final muito elevado.

O impulso nas vendas verificado a partir de 2006 coincide com a criação do programa Procaminhoneiro, do BNDES (Banco Nacional de Desenvolvimento Econômico e Social). Segundo informações da CNT (2013), este programa teve como objetivo facilitar o financiamento da compra de caminhões e implementos, disponibilizando para empréstimos o montante de 9,4 bilhões de reais entre maio de 2006 a dezembro de 2010. No período de 2006 a abril de 2010, foram realizadas aproximadamente 22 mil opera- 
ções de crédito por intermédio do Procaminhoneiro, o que representou um volume de recursos de cerca de 3,8 bilhões de reais.

Consciente da importância da indústria de caminhões para o país, a CNT - juntamente com o Governo Federal e outras entidades - propôs em 2008 a criação do Plano Nacional de Renovação de Frota de Caminhões, o Renovar. De acordo com a CNT (2013), o projeto, com caráter permanente, consubstancia um conjunto de ações que visam, dentre outras coisas: conceder crédito ao caminhoneiro autônomo e microempresas de transporte, incentivar a renovação da frota de caminhões por mais modernos (portanto, menos poluentes) e dar estímulo econômico-financeiro aos integrantes da cadeia produtiva de caminhões.

Alguns estudos que abordam a análise da estrutura de segmentos do ramo automobilístico já foram realizados. Dentre esses, destacam-se Mattos e Barros (2006), que buscaram analisar a estrutura do mercado brasileiro de carros populares, e Sant'Anna (2010), que buscou investigar a evolução da concentração industrial nos setores de automóveis e comerciais leves. Ressalta-se que não foram encontrados estudos que tenham realizado a análise sugerida neste trabalho.

Estudos dessa natureza buscam levantar informações relevantes sobre a participação das firmas no mercado, uma vez que, quanto maior a fatia de mercado absorvida por uma firma, maior tende a ser seu poder de monopólio frente às rivais. Assim, este estudo procura investigar a estrutura do mercado de caminhões no Brasil com base na Teoria da Organização Industrial, que fornece uma metodologia eficaz e esclarecedora para este tipo de análise. A escolha de tal setor deu-se em função da importância do segmento rodoviário para o país (em especial a indústria de caminhões). Isso porque esse último caracteriza-se como um vetor de promoção de desenvolvimento econômico, pois, compreende-se que uma boa estruturação do setor de transportes (especialmente o rodoviário) induz à integração dos demais setores e/ou regiões em toda estrutura produtiva e de distribuição.

Dessa forma, este trabalho teve como objetivo geral analisar o grau de concentração do mercado de caminhões no Brasil no período 1990-2010. Especificamente, o artigo procurou: a) destacar as firmas que possuem a maior parcela do mercado estudado; b) analisar a evolução das vendas das principais firmas; c) averiguar a concentração do mercado; e d) estabelecer considerações sobre barreiras à entrada neste mercado. 
O presente artigo está dividido em quatro seções, além dessa introdução. Na segunda seção apresenta-se o modelo Estrutura-Conduta-Desempenho através de uma breve revisão teórica. A terceira seção apresenta a metodologia e a fonte de dados utilizada neste trabalho. Na quarta seção elabora-se a análise da estrutura do mercado brasileiro de caminhões no período 19902010. A quinta seção apresenta a conclusão do trabalho.

\section{REFERENCIAL TEÓRICO: ESTRUTURA-CONDUTA- DESEMPENHO}

A análise da estrutura do mercado de caminhões no Brasil baseou-se na Teoria da Organização Industrial, que fundamentou o influente paradigma de Estrutura-Conduta-Desempenho (E-C-D). Segundo Brumer (1981), a E-C-D estabelece, em sua forma mais simples, uma relação de causalidade entre os três elementos, onde a Estrutura do mercado influencia o Comportamento das firmas que nele atuam, e este, por sua vez, afeta o Desempenho do mercado.

De acordo com Brumer (1981), existem várias características importantes na análise da estrutura de uma indústria, dentre as quais vale destacar:

a) Grau de concentração dos vendedores - caracterizado em termos do número e distribuição por tamanho das firmas vendedoras no mercado, podendo ser definido como, monopólio, oligopólio ou atomizado. O grau de concentração dos vendedores tem significativa influência sobre o caráter, a intensidade e a efetividade da concorrência num dado mercado.

b) Mudança do tamanho do mercado - atenta-se para o crescimento relativo da produção e das vendas da indústria. Exemplificando, pode existir relação entre o rápido crescimento da indústria e altos níveis de concentração.

c) Grau de diferenciação dos produtos- refere-se aos produtos da mesma indústria que podem apresentar características diferentes, ou seja, bens substitutos imperfeitos. Na realidade, a diferenciação dos produtos é um reflexo das relações de competitividade entre as empresas, vindo a influenciar suas condutas e o desempenho do mercado. 
d) Condição de entrada no mercado - atenta-se para as facilidades ou dificuldades com as quais as novas empresas podem entrar na indústria, determinadas, de modo geral, pelas vantagens que os vendedores estabelecidos têm sobre os ingressantes potenciais.

Segundo Mattos e Barros (2006), o primeiro passo para se analisar a da estrutura é determinar o mercado, que pode ser observado em duas dimensões: tipo de produto e dimensão geográfica.

$\mathrm{Na}$ primeira delas, são considerados no mesmo mercado aqueles produtos tidos como substitutos próximos (neste caso, os caminhões). Muitos critérios são adotados de modo a determinar a substitutibilidade entre dois produtos, dentre eles destaca-se o cálculo da elasticidade cruzada da demanda entre os bens. As características, os preços, a utilização do produto, além do conhecimento dos participantes do mercado são outros indicadores disponíveis para a determinação de mercado segundo o "tipo de produto".

A segunda dimensão - geográfica - define que são considerados no mesmo mercado os produtos comercializados numa mesma localização, sendo esta uma cidade, estado, ou país.

Para a realização deste trabalho foram consideradas todas as empresas associadas à Anfavea que produzem caminhões no território brasileiro e estabeleceram vendas no mercado de atacado interno entre os anos de 1990 e 2010.

Após a determinação do mercado torna-se possível definir quais são os principais elementos que definem sua estrutura. Shepherd (1999) indica que devem ser analisados três elementos: a firma com a maior parcela de mercado; a concentração do mercado; e as condições de entrada de novas firmas no mercado, ou seja, barreira à entrada. Segundo Kon (1994), a mensuração da concentração é capaz de prover ao pesquisador os elementos empíricos necessários para que se possa avaliar a situação de competição de um mercado.

Para Boff e Resende (2002), as medidas de concentração podem ser classificadas como parciais ou sumárias, e como positivas e normativas. As medidas parciais não levam em consideração as informações de todas as firmas na indústria em análise, focando em uma parcela da indústria, geralmente referente às maiores firmas (como exemplo cita-se a Razão de Concentração). Já as medidas sumárias utilizam os dados de todas as firmas 
da indústria, como ocorre, por exemplo, no cálculo do Índice de Herfindahl- Hirschman. As medidas positivas consideram a estrutura aparente do mercado industrial (não considerando qualquer parâmetro comportamental) e dessa forma, elas são o resumo estatístico da concentração, não sendo totalmente adequadas para a análise do desempenho do mercado. Medidas normativas consideram, além da estrutura aparente do mercado, os parâmetros comportamentais, tanto de vendedores quanto de compradores, ou seja, elas englobam análises nos campo da estrutura e da conduta das firmas, contribuindo para uma maior compreensão do desempenho do mercado.

Para a análise da concentração industrial investigada neste trabalho foram adotadas as medidas positivas, dentre as quais vale destacar a Parcela de Mercado, a Razão de Concentração e o Índice de Herfindahl- Hirschman. A utilização dessas medidas para a compreensão da evolução de concentração da indústria necessita que sejam feitas análises mais profundas de questões relacionadas ao desempenho econômico da indústria e das firmas que a compõem. Como ressaltado por Resende (1994), a utilização de medidas relacionadas à oferta (como no caso deste trabalho) apontam como resultado uma forma sintética do poder de mercado das firmas, e acaba resumindo um conceito de múltiplas dimensões, como é o caso da estrutura da indústria, em um único indicador. Dessa forma, há necessidade de que sejam feitas análises posteriores que complementem os resultados dos índices calculados, caso o foco da análise seja avaliar além da estrutura, a conduta e o desempenho das firmas da indústria. No entanto, como no presente estudo o objetivo é analisar a estrutura do mercado nacional de caminhões, as medidas positivas podem ser utilizadas.

De acordo com Mattos e Barros (2006), a distribuição do mercado entre as firmas apresenta-se como o elemento da estrutura que mais tem sido discutido em trabalhos empíricos, dado que a parcela de mercado de cada firma mostra-se como o melhor indicador do poder de monopólio que pode ser exercido pela mesma. Além disso, Aguiar (2003) argumenta que dentre os elementos da estrutura, a distribuição do mercado é aquele que apresenta maior facilidade de ser mensurado, sendo as parcelas de mercado e os índices de concentração os métodos mais frequentes para se realizar tais medidas.

A partir da parcela de mercado de cada firma é possível classificar o mercado através dos critérios adotados por Shepherd (1999). De acordo com 
o autor, um mercado será classificado como um oligopólio forte se a soma das parcelas de mercado das quatro maiores firmas for superior a $60 \%$ do mercado. Valores entre $40 \%$ e $60 \%$ indicam um oligopólio moderado, e, valores abaixo de $40 \%$ denotam oligopólios fracos.

De acordo com Aguiar (2003), as variáveis que são mais utilizadas na determinação da parcela de mercado de cada firma são: valor monetário das vendas, a quantidade vendida por cada firma, capacidade produtiva e o número de empregados.

Quanto às barreiras à entrada, Kon (1994) enfatiza que a possibilidade de entrada de novas firmas em um oligopólio pode alterar tanto os níveis de lucros a serem obtidos quanto o nível de preços. Assim, muitas firmas já estabelecidas no mercado atuam de modo discriminatório perante as firmas entrantes na tentativa de manter seus níveis de lucro inalterados.

Mattos e Barros (2006) sugerem classificar as barreiras à entrada em dois tipos: barreiras de origem exógena e endógena. As fontes exógenas se relacionam às características específicas do mercado, como a tecnologia, natureza do produto, necessidade de capital em grande escala e dos custos irrecuperáveis.

As barreiras endógenas, por sua vez, são criadas pelas firmas líderes com o intuito de inibir a entrada de novas firmas no mercado, dificultando a entrada de novos concorrentes no mercado. Como exemplo desse tipo de barreira nota-se a capacidade ociosa mantida pelas firmas líderes, a criação de patentes, e os elevados gastos com promoção e propaganda. De acordo com Mattos e Barros (2006), esse fator demonstra a capacidade da firma presente no mercado de obter vantagens sobre entrantes em potencial. De modo geral, percebe-se que os gastos com capital são diretamente relacionados com as barreiras à entrada.

\section{METODOLOGIA}

\subsection{Modelo Analítico}

A análise da estrutura do mercado de caminhões no Brasil levou em consideração a distribuição do mercado entre as firmas no período de 1990 a 2010 . 
Conforme citado anteriormente, a parcela de mercado é uma importante ferramenta para se determinar o poder de uma firma dentro do mercado, e pode ser obtida do seguinte modo:

$$
p_{i}=\frac{q_{i}}{\sum_{j=1}^{N} q_{j}}
$$

Em que: $p_{i}$ é a parcela de mercado; $q_{i}$, é a venda total (ou outra variável) da firma $i ; q_{j}$, a venda total (ou outra variável) da firma $j$; e $N$, o número de firmas no mercado.

Determinadas as parcelas de mercado de cada firma, torna-se possível definir a taxa de concentração do mercado (CRk), bem como o índice sumário de Herfindahl- Hirschman (HHI). A taxa de concentração do mercado (CRk) das k maiores firmas é definida por:

$$
C R k=\sum_{i=1} p_{i}
$$

Em que: $C R k$ é a taxa de concentração das $k$-ésimas maiores firmas do mercado e $p_{i}$ representa a parcela de mercado da firma $i$.

Este índice é utilizado para determinar a participação das maiores firmas no total do mercado. Os seus resultados variam entre 0 e 1 , sendo 0 uma situação bem próxima à concorrência perfeita e 1 , monopólio, indicando extrema concentração.

A fácil interpretação e a simplicidade no cálculo são algumas das vantagens apontadas por Kon (1994) na utilização deste índice. A autora também apresenta como deficiência, o fato dele não levar em consideração todas as firmas do mercado. Mattos e Barros (2006) apontam outras duas limitações deste índice: a taxa de concentração não traduz nenhuma referência sobre os respectivos tamanhos das firmas e não considera a mudança de posição das firmas (turnover), o que daria a indicação de um mercado mais competitivo.

A outra medida de concentração adotada neste trabalho foi o Índice de Herfindahl- Hirschman (HHI), que pode ser obtido da seguinte forma: 


$$
H H I=\sum_{i=1}^{K}\left(p_{i}\right)^{2}
$$

Em que: $p_{i}$ é a parcela decimal de mercado de cada uma das firmas e $K$, o número de firmas do mercado.

O HHI considera todas as firmas do mercado. Desse modo, a entrada de novas firmas ou saída de firmas já estabelecidas no mercado afetam o resultado do índice. O valor do resultado final varia entre 1 e $1 / \mathrm{k}$, sendo que um $\mathrm{HHI}=1$ denota a presença de monopólio e $\mathrm{HHI}=1 / \mathrm{k}$, representa situações que variam do oligopólio à concorrência perfeita. A presença de um grande número de firmas no mercado (k elevado) fará com que o índice HHI tenda a zero, ou seja, apresentará uma situação de concorrência perfeita.

De acordo com Resende (1994), o HHI apresenta como vantagens em relação aos outros índices o fato de incorporar o total de firmas da indústria, e não apenas as maiores firmas, sendo que o tamanho relativo das firmas tem peso no resultado final do cálculo. $\mathrm{O}$ índice também é capaz de captar movimentos de fusões de empresas, em termos de aumento do seu valor. Segundo o autor, pode-se definir, a partir de tal índice, o número equivalente de firmas de igual tamanho que levaria ao mesmo índice HHI. Esse número é o inverso desse índice, e é dado por 1/HHI.

\subsection{Fonte de Dados}

Para a mensuração da concentração no setor de caminhões foram utilizados dados referentes à quantidade de unidades vendidas no mercado de atacado brasileiro entre os anos de 1990 e 2010, apresentados pela Anfavea (2013a). Através de levantamentos e estudos anuais, esta associação apresenta informações referentes à produção, vendas e exportações de todas as empresas associadas.

\subsection{Resultados e Discussão}

Inicialmente, determinou-se o mercado de caminhões no Brasil segundo duas dimensões: tipo de produto e dimensão geográfica. Na primeira 
foram considerados todos os veículos automotores configurados como caminhões, com peso bruto total (PBT) superior a 3,5 toneladas, independente de outras características apresentadas. Segundo a Anfavea (2013a), o PBT é utilizado para diferenciar os caminhões entre: semileves, leves, médios, semipesados, e pesados.

Na dimensão geográfica, considerou-se que o mercado de caminhões abrange todo o território brasileiro, uma vez que há concessionárias (postos de venda) das quatro maiores empresas em praticamente todos os estados brasileiros. As únicas exceções foram as empresas Man (fabricante dos caminhões Volkswagen), que não possui concessionária no estado do Acre, e a Scania, que não apresenta concessionárias nos estados de Roraima e Tocantins.

Definidas as dimensões do mercado de caminhões, a análise de sua estrutura segue com a determinação das parcelas de mercado de cada firma. A parcela de mercado foi determinada pelo número de unidades vendidas no mercado interno brasileiro, no período de 1990 a 2010. A Tabela 1 apresenta a evolução das vendas de caminhões no período abordado.

Tabela 1 - Número de caminhões vendidos no mercado interno brasileiro, 1990-2010

\begin{tabular}{ccccccc}
\hline ANO & Mercedes-Benz & Ford & Man & Scania & Outros & Total \\
\hline 1990 & 13.539 & 9.710 & 7.106 & 3.730 & 7.228 & 41.313 \\
1991 & 17.848 & 9.012 & 5.408 & 3.400 & 5.796 & 41.464 \\
1992 & 10.719 & 5.010 & 2.981 & 3.211 & 3.738 & 25.659 \\
1993 & 14.600 & 5.656 & 5.113 & 5.080 & 7.320 & 37.796 \\
1994 & 20.668 & 6.621 & 8.381 & 6.499 & 8.240 & 50.409 \\
1995 & 22.110 & 10.215 & 10.636 & 5.908 & 8.094 & 56.963 \\
1996 & 16.312 & 7.536 & 7.417 & 5.149 & 4.159 & 40.573 \\
1997 & 19.357 & 11.334 & 8.337 & 6.977 & 6.300 & 52.305 \\
1998 & 18.410 & 10.723 & 8.700 & 5.200 & 6.886 & 49.919 \\
1999 & 16.826 & 10.476 & 9.573 & 4.393 & 5.638 & 46.906 \\
2000 & 22.005 & 12.082 & 13.660 & 5.335 & 8.542 & 61.624 \\
2001 & 21.135 & 13.114 & 17.844 & 5.428 & 12.988 & 70.509
\end{tabular}




\begin{tabular}{ccccccc}
\hline ANO & Mercedes-Benz & Ford & Man & Scania & Outros & Total \\
\hline 2002 & 20.026 & 14.182 & 18.184 & 3.235 & 8.595 & 64.222 \\
2003 & 21.005 & 13.269 & 20.752 & 4.127 & 7.210 & 66.363 \\
2004 & 23.925 & 16.528 & 25.053 & 6.094 & 11.121 & 82.721 \\
2005 & 22.847 & 15.874 & 23.532 & 5.225 & 9.782 & 77.260 \\
2006 & 21.783 & 14.671 & 22.404 & 5.062 & 8.685 & 72.605 \\
2007 & 27.984 & 18.585 & 29.676 & 6.505 & 13.897 & 96.647 \\
2008 & 34.424 & 21.902 & 37.112 & 8.008 & 20.201 & 121.647 \\
2009 & 30.426 & 21.497 & 34.341 & 8.324 & 16.013 & 110.601 \\
2010 & 43.230 & 29.627 & 48.649 & 15.411 & 29.406 & 166.323 \\
\hline
\end{tabular}

Fonte Anfavea (2013a).

A partir dos dados apresentados na Tabela 1 foi possível ordenar as firmas quanto à evolução de suas vendas no mercado interno. A Man destaca-se por ter apresentado um acréscimo de 584,6\% em suas vendas durante o período, sendo seguida pela Scania, com $313,7 \%$ e pela Mercedes-Benz, $\operatorname{com} 219,3 \%$. A Ford foi a firma que apresentou o menor crescimento dentre as que mais venderam $(205,1 \%)$. As outras firmas que compõem o mercado quadruplicaram suas vendas (conjuntamente) durante o período.

De acordo com o número de unidades vendidas por cada uma das firmas foi possível determinar suas respectivas parcelas de mercado. Assim, é possível observar de modo mais detalhado como o mercado esteve distribuído entre as firmas durante o período analisado. Os resultados obtidos encontram-se na Tabela 2.

Tabela 2 - Parcela de mercado (em \%) das firmas no mercado brasileiro de caminhões, 1990-2010

\begin{tabular}{cccccc}
\hline ANO & Mercedes- Benz & Ford & Man & Scania & Outros \\
\hline 1990 & 32,77 & 23,50 & 17,20 & 9,03 & 17,50 \\
1991 & 43,04 & 21,73 & 13,04 & 8,20 & 13,99 \\
1992 & 41,77 & 19,53 & 11,62 & 12,51 & 14,57 \\
1993 & 38,66 & 14,98 & 13,54 & 13,45 & 19,37 \\
1994 & 41,00 & 13,13 & 16,63 & 12,89 & 16,35
\end{tabular}




\begin{tabular}{cccccc}
\hline ANO & Mercedes- Benz & Ford & Man & Scania & Outros \\
\hline 1995 & 38,81 & 17,93 & 18,67 & 10,37 & 14,22 \\
1996 & 40,20 & 18,57 & 18,28 & 12,69 & 10,26 \\
1997 & 37,01 & 21,67 & 15,94 & 13,34 & 12,04 \\
1998 & 36,88 & 21,48 & 17,43 & 10,42 & 13,79 \\
1999 & 35,87 & 22,33 & 20,41 & 9,37 & 12,02 \\
2000 & 35,71 & 19,61 & 22,17 & 8,66 & 13,85 \\
2001 & 29,97 & 18,60 & 25,31 & 7,70 & 18,42 \\
2002 & 31,18 & 22,08 & 28,31 & 5,04 & 13,39 \\
2003 & 31,65 & 19,99 & 31,27 & 6,22 & 10,87 \\
2004 & 28,92 & 19,98 & 30,29 & 7,37 & 13,44 \\
2005 & 29,57 & 20,55 & 30,46 & 6,76 & 12,66 \\
2006 & 30,00 & 20,21 & 30,86 & 6,97 & 11,96 \\
2007 & 28,95 & 19,23 & 30,71 & 6,73 & 14,38 \\
2008 & 28,30 & 18,00 & 30,51 & 6,58 & 16,61 \\
2009 & 27,51 & 19,44 & 31,05 & 7,53 & 14,47 \\
2010 & 25,99 & 17,81 & 29,25 & 9,27 & 17,68 \\
\hline
\end{tabular}

Fonte: Resultados da pesquisa de acordo com os dados da Anfavea (2013a).

Conforme pode ser observado na Tabela 2, a Mercedes-Benz manteve a maior parcela de mercado até o ano de 2003, sendo superada pela Man no ano seguinte. Embora novas firmas tenham entrado e saído do mercado durante o período analisado, a Man manteve sua posição como a detentora de maior parcela de mercado entre os anos de 2004 até 2010. Vale

ressaltar que esta firma vem ganhando mercado frente às rivais, uma vez que ao longo desse período ultrapassou a Ford (em 2000) e a Mercedes -Benz (em 2004) no número de vendas no mercado interno. A Man também foi a firma que mais aumentou sua participação no mercado, passando de 17,2\% em 1990, para 29,25\% em 2010. Desse modo, verifica-se que uma das características desse mercado é o baixo turnover, ou seja, nota-se poucas trocas de posições entre as firmas ao longo do período abordado, principalmente na disputa pela primeira posição no ranking do mercado (nota-se apenas uma troca). Este fato pode ser verificado no Gráfico 2, que apresenta a evolução da parcela de mercado das quatro maiores firmas. 
Gráfico 2 - Evolução da parcela de mercado das quatro maiores firmas no mercado brasileiro de caminhões, 1990-2010

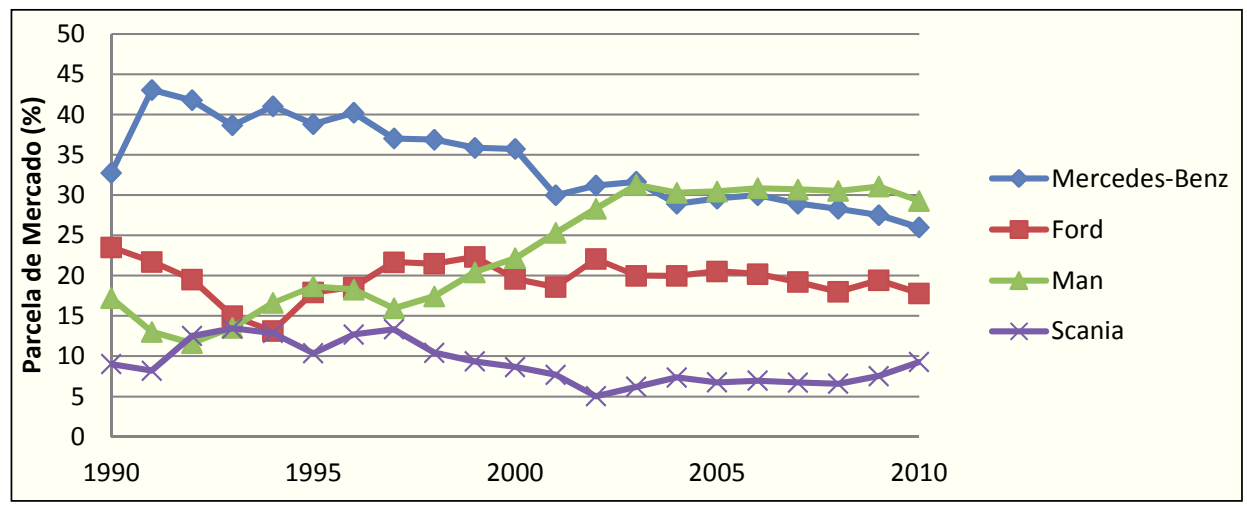

Fonte: Resultados da pesquisa.

O Gráfico 2 também evidencia a tendência de perda de mercado por parte da Mercedes-Benz, que em 1991 detinha 43,04\% da parcela deste em 2010, apenas 25,99\%. A Ford e a Scania, também alteraram suas posições no ranking. A primeira alternou junto com a Man a segunda e a terceira colocação até 1999, e a segunda, embora tenha permanecido na quarta posição ao longo de quase todo o período, conseguiu superar por pouco a colocação da Man no ano de 1992.

Dentre as firmas que entraram e saíram do mercado nesse período destacam-se a Fiat, que permaneceu no mercado entre os anos de 2000 e 2007; a International no período 1998-2002 e a Peugeot/Citroen no curto período 2002-2005. A Iveco estabeleceu suas vendas no mercado interno a partir do ano 2000 e se mantem no mercado até os dias atuais. Através da observação dos dados pode-se notar que todas estas firmas absorveram pequenas parcelas do mercado de caminhões durante o período em que realizaram suas atividades nesse setor. A entrada e saída dessas firmas no mercado foi um dos principais causadores das oscilações nas parcelas de mercado do grupo de firmas chamado "Outros", apresentado na Tabela 2.

Após a análise das parcelas de mercado buscou-se compreender a evolução da concentração de mercado através do cálculo das taxas de concentração e do índice sumário de Herfindahl-Hirschman. Para a análise das taxas de concentração foram considerados o CR3 e o CR4, geralmente 
utilizado para classificar mercados oligopolizados. Os resultados encontramse expressos na Tabela 3.

Tabela 3 - Taxas de concentração e índice sumário de Herfindahl-Hirschman do mercado brasileiro de caminhões, 1990-2010

\begin{tabular}{llll}
\hline ANO & CR3 & CR4 & HHI \\
\hline 1990 & 73,47 & 82,50 & 0,2112 \\
1991 & 77,81 & 86,01 & 0,2633 \\
1992 & 72,92 & 85,43 & 0,2520 \\
1993 & 67,18 & 80,63 & 0,2253 \\
1994 & 70,76 & 83,65 & 0,2419 \\
1995 & 75,41 & 85,78 & 0,2388 \\
1996 & 77,05 & 89,74 & 0,2529 \\
1997 & 74,62 & 87,96 & 0,2348 \\
1998 & 75,79 & 86,21 & 0,2319 \\
1999 & 78,61 & 87,98 & 0,2351 \\
2000 & 77,49 & 86,15 & 0,2293 \\
2001 & 73,88 & 81,58 & 0,2033 \\
2002 & 81,57 & 86,61 & 0,2348 \\
2003 & 82,91 & 89,13 & 0,2474 \\
2004 & 79,19 & 86,56 & 0,2285 \\
2005 & 80,58 & 87,34 & 0,2345 \\
2006 & 81,07 & 88,04 & 0,2389 \\
2007 & 78,89 & 85,62 & 0,2294 \\
2008 & 76,81 & 83,39 & 0,2226 \\
2009 & 78,00 & 85,53 & 0,2254 \\
2010 & 73,05 & & \\
\hline
\end{tabular}

Fonte: Resultados da pesquisa.

De acordo com os dados apresentados na Tabela 3, pode-se constatar que não houve tendência relevante quanto à concentração ou a desconcentração do mercado. Tanto os valores do CR3, CR4 e HHI mantiveram-se, de certo modo, distribuídos próximos da média ao longo do período analisado. 
O CR3, que em 1990 era igual a 73,47, apresentava em 2010 o valor de 73,05. Embora tenha havido períodos onde ocorreram elevações na taxa de concentração, o CR3 representou em média, valor de 76,52, dando clara indicação da forte oligopolização deste mercado.

O CR4 apresentou um comportamento ainda mais estável que o CR3, com média de $85,6 \%$ durante o período. De acordo com a classificação de Shepherd (1999), que utiliza o CR4 como parâmetro, pode-se notar que este mercado é fortemente oligopolizado. As quatro maiores firmas dominam cerca de $85,6 \%$ do mercado enquanto as outras sete firmas analisadas neste trabalho, dividiram em média, a parcela de $14,4 \%$ ao longo do período. A evolução das taxas de concentração pode ser verificada no gráfico abaixo.

Gráfico 3 - Evolução das taxas de concentração no período 1990-2010

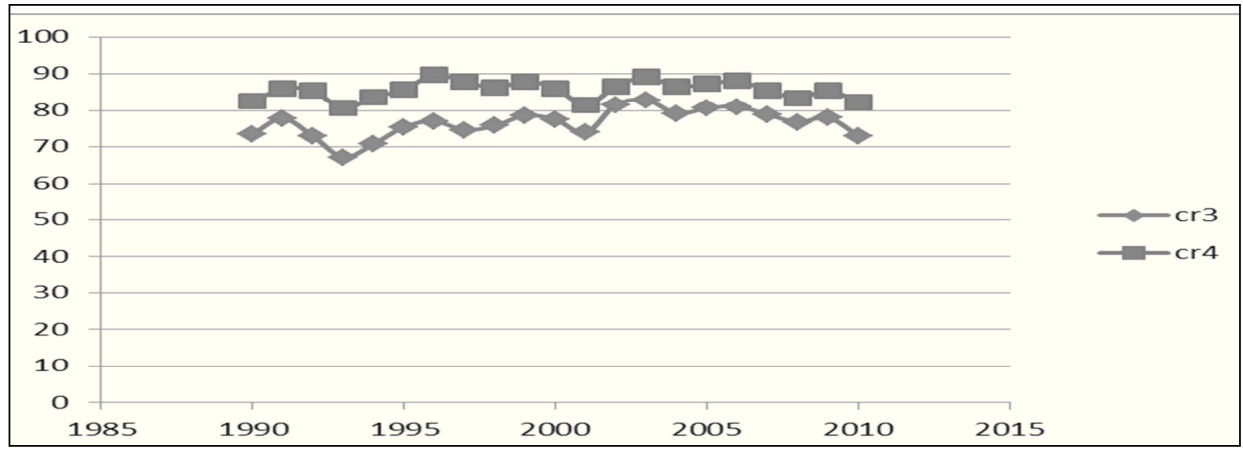

Fonte: Resultados da pesquisa.

O índice Herfindahl-Hirschman (HHI), embora tenha apresentado maiores variações que o CR3 e CR4 ao longo do período, também não mostrou clara indicação quanto à tendência de concentração/desconcentração do mercado, conforme pode ser observado no Gráfico 4. Em 1990 o HHI apresentava o valor de 21,12 e em 2010 seu valor era igual a 20,84, caracterizando uma variação de 1,32\%. O CR3 apresentou uma variação de $0,57 \%$, e o CR4, o mais estável dos indicadores, exibiu uma variação de apenas $0,22 \%$ ao longo do período.

Dessa forma, observou-se que embora novas firmas tenham entrado no mercado, não se observou expressiva redução da concentração, uma vez que, as entrantes absorveram uma ínfima parcela do mesmo. 
A partir do HHI é possível determinar o número de firmas iguais que atenderiam todo o mercado. O valor de 0,2084 , em 2010, indicou que haveria apenas 4,8 firmas iguais nesse mercado, o que dá indícios de forte concentração e facilidade de cooperação entre elas.

Destaca-se que apesar da existência de quatro firmas principais, tal número foi próximo de cinco. Uma possível explicação para isso é que embora as firmas que não compõem o CR4 não sejam importantes individualmente em termos de participação no mercado, pode-se notar que estas, em conjunto, representam parcela semelhante à uma empresa pertencente ao CR4. Conforme pode ser observado na Tabela 2, no ano de 2010 o grupo Outros (grupo que compõe todas as firmas não pertencentes ao CR4) apresentou parcela de mercado de $17,68 \%$, enquanto a Ford apresentou uma parcela de 17,81\%.

Gráfico 4 - Evolução do HHI no período 1990-2010

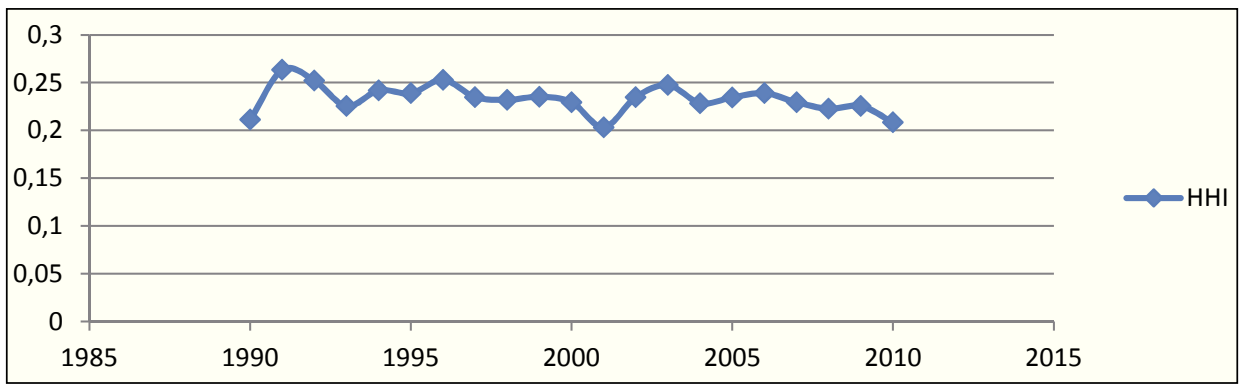

Fonte: Resultados da pesquisa.

Com relação às barreiras à entrada, pode-se identificar algumas características próprias do setor automobilístico como entraves à entrada de novas firmas; uma vez que as empresas que são foco de análise neste estudo atuam em outros segmentos do mercado automobilístico. Segundo Rotta e Bueno (2000), o setor automobilístico é caracterizado pela presença de economias de escala multi-planta. Isso significa que para as empresas já estabelecidas no mercado é vantajoso instalar unidades produtivas em outros lugares à medida que o custo de capital para elas é extremamente menor ao custo para empresas sem essa característica que ingressam no mercado. 
A necessidade de elevada quantia de capital também é uma forte barreira à entrada de novas firmas, conforme sugerem Mattos e Barros (2006). Segundo argumentam os autores, no ano de 2002, o setor de fabricação e montagem de veículos automotores apresentou um ativo total superior a $\mathrm{R} \$ 8,5$ bilhões. Desse modo fica explícita a necessidade de elevado aporte de capital para que uma firma possa ingressar neste mercado.

Gastos com propaganda também são considerados como uma barreira à entrada. Quanto mais expressivos, maiores as chances do mercado estar em situação de elevada competição. Segundo o ranking divulgado pelo site da revista Exame (2013), dentre as 20 maiores empresas a realizar investimentos em publicidade no ano de 2011, seis são pertencentes ao setor automobilístico, dando clara indicação do alto grau de competitividade nesse setor.

Finalizando, a capacidade ociosa mantida pelas empresas já estabelecidas também apresenta-se como um dos fatores que barra a entrada de novas firmas. Segundo dados da Confederação Nacional do Transporte (CNT,2013), o setor de caminhões apresentava uma capacidade produtiva de aproximadamente 210 mil veículos em 2009. No entanto, ocorreu a produção de cerca de apenas 123 mil caminhões. O setor operou com uma capacidade ociosa de aproximadamente 86 mil veículos nesse ano. Vale ressaltar que essa capacidade ociosa elevada pode ser um reflexo da crise econômica internacional, que estendeu seus efeitos sobre a economia brasileira. No entanto, de acordo com os dados apresentados pelo CNT (2013), pode-se notar que o setor já vinha operando com capacidade ociosa desde 2007, ano anterior à crise, o que pode evidenciar que esta é uma característica importante do setor.

\section{CONCLUSÃO}

Este trabalho buscou investigar quais são os principais elementos que caracterizam a estrutura de mercado do setor de caminhões no Brasil entre os anos de 1990 e 2010. Para isso, verificou-se de que forma ocorreu a evolução da concentração nesta indústria, além da elaboração de considerações sobre as barreiras à entrada que atuam neste mercado.

Os resultados observados neste trabalho apontaram que, apesar do mercado brasileiro de caminhões não ter apresentado tendência de concentração/desconcentração durante o período 1990/2010, o mesmo encontra-se 
fortemente oligopolizado de acordo com os critérios adotados por Shepherd (1999). Ressalta-se que na análise deste trabalho foram considerados somente os caminhões produzidos no Brasil e vendidos no mercado de atacado interno durante o período abordado. A incorporação do mercado externo de caminhões, principalmente os importados, pode revelar novas e relevantes informações sobre a estrutura de mercado desse setor.

Foram também feitas considerações sobre as barreiras à entrada de novas firmas nesse mercado. As principais variáveis analisadas tais como presença de economias de escala, gastos com publicidade e propaganda, elevado aporte de capital e grau de capacidade ociosa, apontaram a presença de barreiras nesse mercado.

É importante salientar que este trabalho visou analisar somente a estrutura de mercado do setor de caminhões, fornecendo subsídios para análises posteriores. Como sugestão para futuros trabalhos, propõe-se considerar análises sobre a conduta das firmas e o desempenho do mercado. Isso porque é importante expor como caminham as atividades, as tendências do setor, bem como as estratégias adotadas pelas empresas para que se possa obter uma compreensão mais ampla e detalhada desse importante setor da economia.

A realização de estudos que componham novas perspectivas e informações sobre este setor mostra-se de grande importância, pois, desse modo, pode-se criar mecanismos voltados à melhoria do desempenho dos transportes no país - em especial o rodoviário - ajudando a promover, deste modo, o desenvolvimento econômico do país.

\section{ANALYSIS OF THE STRUCTURE OF THE BRAZILIAN TRUCK MARKET, 1990-2010}

\section{Abstract}

This article aims to analyze the market structure of the Brazilian trucking industry from 1990 to 2010, as this sector proves to be of fundamental importance to the economic development of the country to promote the integration of other sectors and/or regions throughout the production and distribution structure. The theoretical framework used for the analysis was based on the Industrial Organization approach under the Paradigm 
Structure-Conduct-Performance, aiming to investigate the main elements that characterize the structure of the market, among them: the market share, the concentration ratio and summary index Herfindahl-Hirschman. Data for the analysis were obtained from publications Anfavea (National Association of Automobile Manufacturers). The analysis allowed the conclusion that the market studied is heavily oligopoly, and present barriers to entry for new firms.

Keywords: Market Structure, Herfindahl-Hirschman Index, Barriers to Entry

JEL Classification: L1; L11; L62

\section{REFERÊNCIAS}

AEB. Associação de Comércio Exterior do Brasil. Radiografia do Comércio Exterior Brasileiro: Passado, Presente e Futuro. Rio de Janeiro. 2012. Disponível em: <http:/www.cnc.org.br/noticias/aeb-lanca-radiografia-docomercio-exterior-brasileiro $>$. Acesso em: junho de 2014.

AGUIAR, D. R. D. Organização Industrial: O paradigma estrutura-condutadesempenho e a escola de Chicago. Viçosa, 2003. Mimeografado.

ANFAVEA. Anuário da Indústria Automobilística Brasileira - 2012. São Paulo: Associação Nacional dos Fabricantes de Automóveis. Disponível em: <http://www.anfavea.com.br/anuario.html >. Acesso em: Janeiro de 2013. 2013a.

. Indústria Automobilística Brasileira - 50 Anos (Os Caminhões). Disponível em: <http://www.anfavea.com.br/50anos.html>. Acesso em: Janeiro de 2013. 2013b.

BOFF, H.; RESENDE, M. Concentração Industrial. In: HASENCEVER, Lia; KUPFER, D. (Org.). Economia Industrial: fundamentos teóricos e práticos no Brasil. Rio de Janeiro: Campus, 2002. P. 73-90. 
BRUMER, S. Estrutura, conduta e desempenho de mercado na indústria metal- mecânica gaúcha - 1977. Porto alegre: Fundação de Economia e Estatística, 1981.

CNT. RenovAr: Plano Nacional de Renovação de Frota de Caminhões - 2010. Disponível em: <http://www.cnt.org.br/Imagens\%20CNT/RenovAr_dez_2010.pdf> Acesso em: Fevereiro de 2013.

EXAME.COM. Os Trinta Maiores Anunciantes do Brasil em 2011. Disponível em: <http://exame.abril.com.br/marketing/ranking-anunciantes-ibope-2011/>. Acesso em: Fevereiro de 2013.

GABAN, A. C. Panorama do Transporte de Commodities Agrícolas no Brasil. Grupo de Pesquisa e Extensão em Logística Agroindustrial - ESALQ-LOG. Piracicaba. 2013. Disponível em: < http://esalqlog.esalq.usp.br/ files/biblioteca/737.pdf>. Acesso em: Junho de 2014.

GITAHY, L.; BRESCIANI, L. P. Reestruturação Produtiva e Trabalho na Indústria Automobilística Brasileira. Disponível em: $<$ http://www.ige.unicamp.br/site/htm/02_04_05.php?f=11>.

Acesso em: Abril de 2014.

KON, A. Economia Industrial. São Paulo: Nobel, 1994. P. 59-61.

MATTOS, L. B.; BARROS, Á. M. Análise da Estrutura do Mercado Brasileiro de Carros populares, 1990-2005. Revista de Economia e Agronegócio, VOL.4, n.3. Viçosa. 2006.

RESENDE, M. Medidas de Concentração Industrial: uma resenha. Revista Análise Econômica, Porto Alegre, v.12, n.21/22, p.24-33, mar./set. 1994.

ROTTA, I. S.; BUENO, F. Análise Setorial da Indústria Automobilística: Principais Tendências. ENEGEP (Encontro Nacional de Engenharia de Produção). São Paulo. Anais do XX ENEGEP, CD 1, 2000. 
SANT'ANA, L. R. Análise da Concentração na Indústria Automobilística Brasileira nas Décadas de 1990 e 2000. UFRGS. Porto Alegre. 2010.

SHEPHERD, W. G. The Economics of Industrial Organization. Illinois: Waveland Press, 1999. P. 47. 